\title{
Removal of Bisphenol, Using Antimony Nanoparticle Multi-walled Carbon Nanotubes Composite from Aqueous Solutions
}

\author{
MOHAMMAD TAGHI SAMADI ${ }^{1}$, REZA SHOKOOHI ${ }^{1}$, ALI POORMOHAMMADI ${ }^{2}$, \\ GHASEM AZARIAN ${ }^{1}$, MOTAHARE HARATI ${ }^{3}$ and SAMANE SHANESAZ ${ }^{1 *}$
}

${ }^{1}$ Department of Environmental Health Engineering, Faculty of Health and Research Center for Health sciences, Hamadan University of Medical Sciences, Hamadan, Iran.

${ }^{2}$ Social Development \& Health Promotion Research Center, Kermanshah

University of Medical Sciences, Kermanshah, Iran.

${ }^{3}$ Department of Environmental Health Engineering, School of public Health, Iran

University of Medical Science, Iran, Iran.

${ }^{*}$ Corresponding author E-mail: shanesaz.samane@yahoo.com

http://dx.doi.org/10.13005/ojc/320227

(Received: March 07, 2016; Accepted: April 07, 2016)

\section{ABSTRACT}

This study focuses on preparing Antimony Nanoparticle Multi-walled Carbon (ANMWC) composite as an effective adsorbent and then the effect of produced composite in BPA removal from aqueous solutions was studied. ANMWC were prepared using chemical method and characterized with X-ray diffraction (XRD), Fourier-transform infrared spectroscopy (FTIR) and Brunauer-EmmettTeller (BET). Moreover, the removal efficiency of prepared AMWCNT and Nanoparticle Multi-walled Carbon (MWCNT) in removal of Bisphenol A was investigated. Results revealed that the BPA removal efficiency by AMWCNT increased from 80 to $93 \%$ with the increase of contact time 5 to $60 \mathrm{~min}$. The maximum removal efficiency for the both adsorbents was seen at $\mathrm{pH} 7$, which was $85 \%$ for MWCNT and $95 \%$ for ANMWC composite. According to the results obtained, $\mathrm{pH}_{\mathrm{zpc}}$ for both adsorbents was 7. Results showed that the adsorption process followed the pseudo-first order model with a high correlation value and BPA adsorption on MWCNT followed the Langmuir isotherm model.

Keywords: Bisphenol, Adsorption, Nanoparticle Multi-walled Carbon Nanotubes, composite.

\section{INTRODUCTION}

Bisphenol A (BPA) is one the most widely used chemical compounds as a raw material in the product of polycarbonate and epoxy resins
1. BPA can release into the environment through its use and handling, and permitted discharges ${ }^{2}$. Recently, this compound and its derivatives have been found to be widely distributed in the natural environment, as well as in surface water ${ }^{3}$. Due to the 
high toxicity of phenolic compounds to humans, their removal has been taken a huge attention of many researchers ${ }^{4}$.

In recent years, nanotechnology has been taken into huge consideration as a promising technology to treat water. According to the literature, Multi-walled carbon nanotubes (MWCNTs) have shown an ability to efficiently remove various organic pollutants such as dioxins, polychlorinated dibenzo-furans and biphenyls from aqueous environments ${ }^{5,6}$.

Nowadays, considerable efforts have been made to produce metal-carbon nanocomposite materials, not only because the carbonic compound improves the mechanical properties of the composites, but also because the produced composites possess the properties of individual components with a synergistic effect ${ }^{7,8}$.

Therefore, the present work focuses on preparing ANMWC composite as an effective adsorbent and then the effect of produced composite in BPA removal from aqueous solutions was studied. ANMWC were prepared using chemical method and characterized with X-ray diffraction (XRD), Fourier-transform infrared spectroscopy (FTIR) and Transmission Electron Microscope (TEM).

\section{MATERIALS AND METHODS}

\section{Chemicals}

Bisphenol-A was obtained from Merck (Germany). The MWCNT used in this study was obtained from Nutrieno Co. (Tehran, Iran, http:// parscenter.com/Company/CMP645327). Sodium dodecyl sulfate, Antimony powder, Sodium sulfate anhydrous, Sodium hydride powder, Sodium

Table 1: Characteristics of MWCNTs

\begin{tabular}{lcc}
\hline Parameter & Unit & Amount \\
\hline Appearance & - & Black powder \\
External diameter & $\mathrm{nm}$ & $20-30$ \\
Length & $\mu \mathrm{m}$ & 30 \\
Purity carbon & $\%$ & 95 \\
specific surface area & $\mathrm{m}^{2} / \mathrm{g}$ & 110 \\
Density & $\mathrm{g} / \mathrm{cm}^{3}$ & 2.1 \\
\hline
\end{tabular}

Borohydride powder and other chemicals were purchased from Merck.

\section{Preparation and Characterization of adsorbents}

To produce Antimony Nanoparticle Multiwalled Carbon (ANMWC) composite Ultrasonic device was used. The device consist of a stainless steel reactor equipped with a transformer and an ultrasonic wave generator. Table 2 shows the characteristics of used Ultrasonic device.

To prepare ANMWC composite, $100 \mathrm{mg}$ of nanoparticle multi-walled carbon and $40 \mathrm{mg}$ of sodium dodecyl sulfate (as surfactant) were dissolved in $100 \mathrm{ml}$ of pure ethanol. The solution was mixed by Ultrasonic device for $20 \mathrm{~min}$. Next, $80 \mathrm{mg}$ of Sodium Borohydride was added to the solution. Again, the mixtures were mixed for 20 min. Then Antimony solution $(17.5 \mathrm{mmol} / \mathrm{L})$ were gradually added to the nanoparticle multi-walled carbons. Finally, the products were placed into the Ultrasonic devise for $1 \mathrm{~h}$ under stirring conditions. The products were then filtered and washed with doubly distilled water and then dried at $60^{\circ} \mathrm{C}$ in an oven for $12 \mathrm{~h}^{9}$.

In order to obtain the characterization of adsorbent X-Ray Diffraction (XRD, ITALSTRUCTRE, model ADP 2000, Italy) was used. Fourier Transform Infrared Spectroscopy (FTIR, Perkin Elmer Spectrum) was employed in order to determine the functional groups and the chemical structure on surface area of adsorbent materials before and after modification.

Table 2: Characteristics of used Ultrasonic device

\begin{tabular}{ll}
\hline model & LUC-405 \\
\hline time & $0-99 \mathrm{~min}$ \\
temperature & $0-50 \mathrm{0c}$ \\
Frequency & $40 \mathrm{KHZ}$ \\
capacity & $5 \mathrm{~L}$ \\
volume capacity & $300 \times 55 \times 150 \mathrm{~mm}$ \\
useful volume & $300 \times 285 \times 255 \mathrm{~mm}$ \\
power & 350 \\
chamber material & Stainless steel \\
devise body material & $\mathrm{ABS}$ \\
country & Korea \\
voltage & $100 \mathrm{to} 240 \mathrm{v}-\mathrm{AC}$, \\
& $50 / 60 \mathrm{~Hz}$ \\
\hline
\end{tabular}


Moreover, Transmission Electron Microscope (TEM) was used in order confirm the adsorbent modification. Moreover, pHzpc of the synthesized composite and nanoparticle multi-walled carbon was determined using the $\mathrm{pH}$ drift method ${ }^{10}$.

\section{Batch experiments}

To determine the optimum conditions for BPA removal by ANMWC composite, the effect of some operational parameters on the adsorption efficiency was studied. Experimental stages are summarized in Table $3^{10-14}$.

\section{BPA residual concentration}

After adsorption process BPA residual concentration was measured using a spectrophotometer (Uv/Vis spectrometer-DR 5000, Germany) at a wavelength of $276 \mathrm{~nm}^{15,16}$. Eventually,

Table 3: Experimental set-up (experiment steps)

\begin{tabular}{lccc}
\hline Parameters & Unit & Range \\
\hline 1 & Contact time & $\min$ & $50,80,100$, \\
& & & 150 and 200 \\
2 & $\mathrm{pH}$ & $\mathrm{mg} / \mathrm{L}$ & 100,2 and 10 \\
3 & Synthesized & & \\
& adsorbent concentration & $\mathrm{mg} / \mathrm{L}$ & 20,60 and 400 \\
4 & Initial BPA concentration & & \\
\hline
\end{tabular}
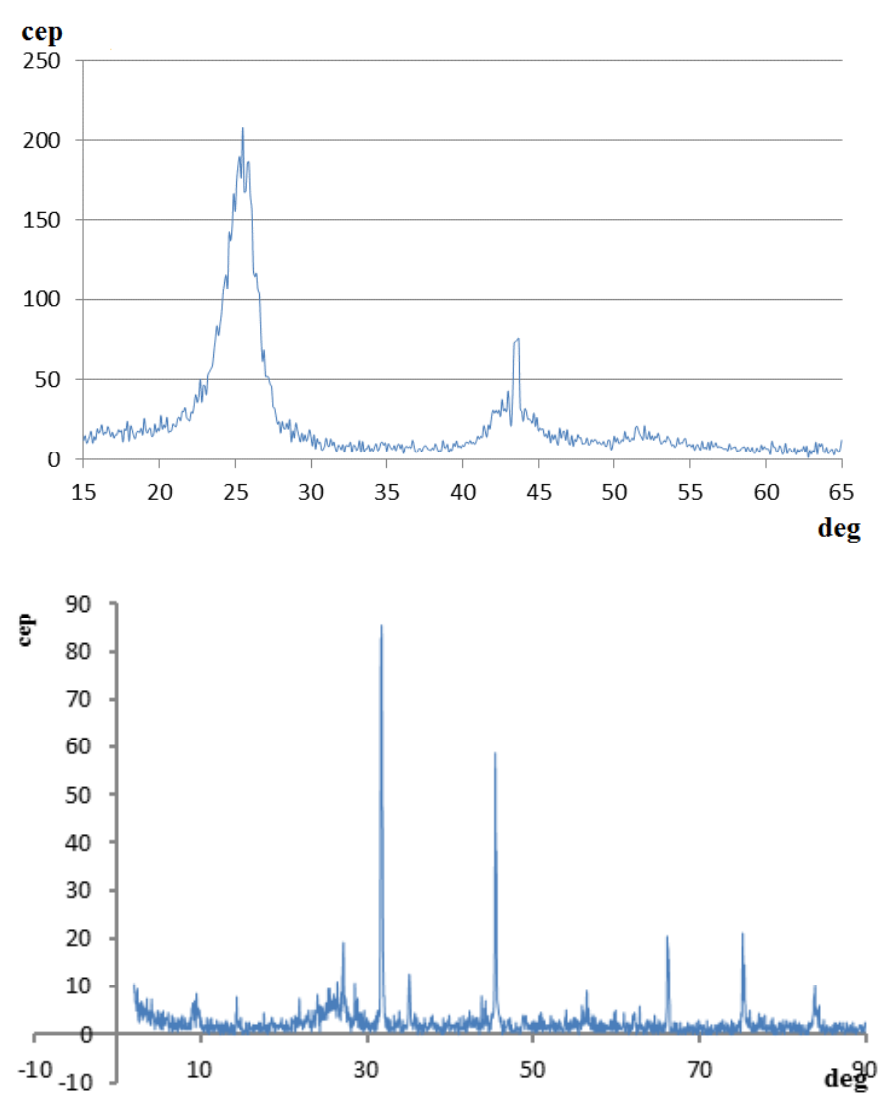

Fig. 1: XRD patterns of (a) MWCNT (b) ANMWC composite 
BPA efficiency was calculated according to the following equation ${ }^{12}$.

$$
R(\%)=\left(\frac{C_{0}-C_{t}}{C_{0}}\right) \times 100
$$

$\mathrm{C}_{0}$ : initial concentration of the BPA $(\mathrm{mg} / \mathrm{L})$

$\mathrm{C}_{\mathrm{t}}$ : instant concentration of the BPA $(\mathrm{mg} / \mathrm{L})$

$R \%$ : Percentage of BPA removal

\section{RESULTS AND DISCUSSION}

The XRD patterns are shown in fig. 1 (a, b). As can be seen in fig. 1 (a), a peak around 25 indicated the presence of carbon, the peak around 43 , indicated the presence of oxygen and peaks between 65 and 85 indicated the presence of antimony. Fig. 1 (b) and the presence of antimony element in the composition of MWCNTs confirms the claim that the ANMWC composite was properly prepared. This result is consistent with the finding of Fernando et ap.

\section{Characterization of adsorbents}

Fig. 2 shows the FTIR spectra of both adsorbents (MWCNT and ANMWC composite) before and after adsorption process. As revealed, a broad peak around $3400 \mathrm{~cm}^{-1}$ correspond to the presence of $\mathrm{O}-\mathrm{H}$ groups on the MWCNT surface. This figure showed peaks at 1623 and $1637 \mathrm{~cm}^{-1}$ which indicted the presence of aromatic structures $\mathrm{C}=\mathrm{O}$ in the MWCNT. These results are consistent with the results of the FTIR spectrum obtained by Zazoli et al. on the application of L-cysteine functionalized singlewalled carbon nanotubes for removing mercury from aqueous solutions ${ }^{15}$. After adsorption process a peak around $1223 \mathrm{~cm}^{-1}$ indicated the presence of phenolic band $\mathrm{C}-\mathrm{O}$, which indicated that BPA has been
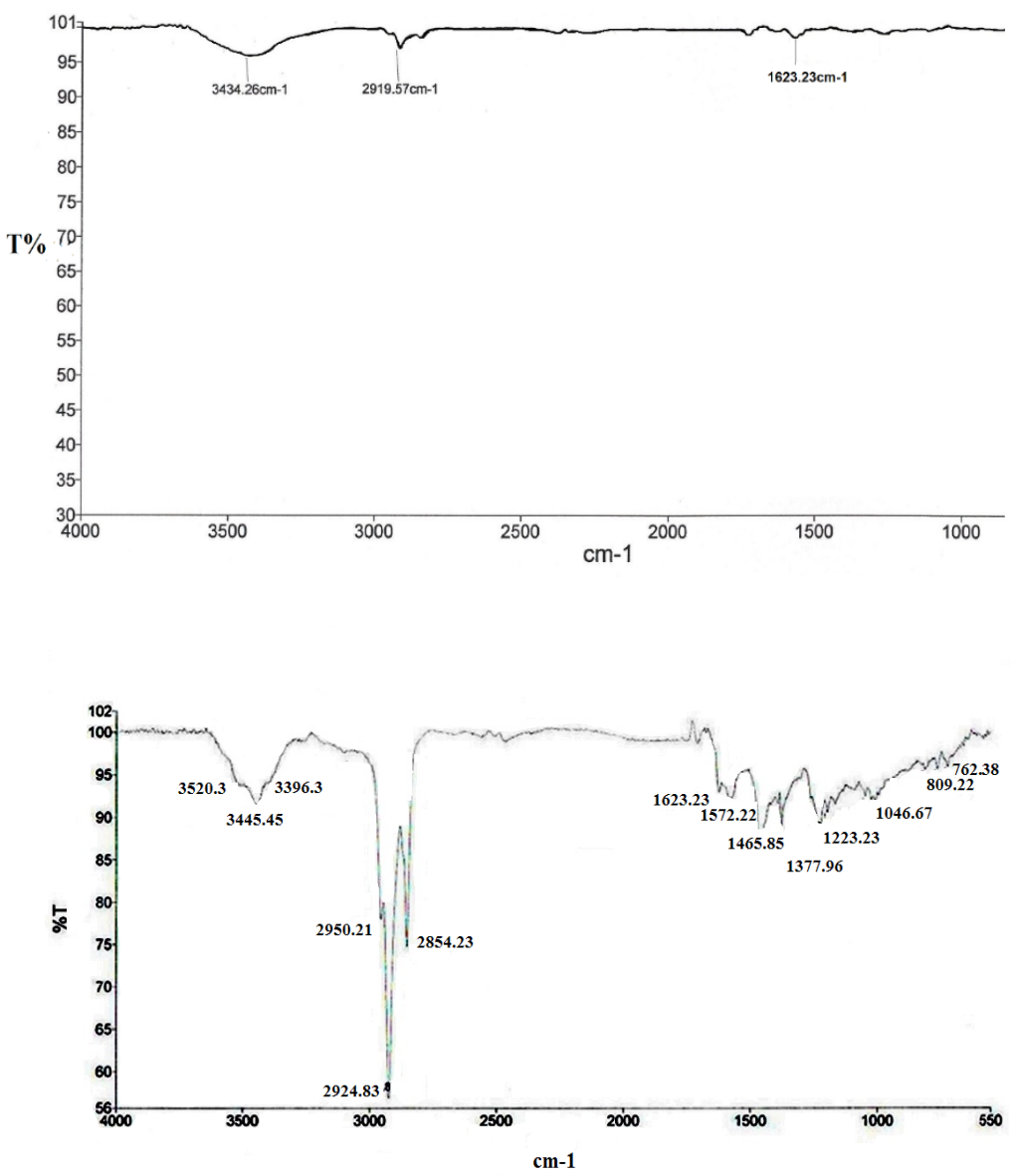

Fig. 2: FTIR spectra of MWCNT (a) before and (a) after adsorption process 
adsorbed on the adsorbent surface. In spectrum of the carbon nanotubes modified with antimony, a peak at $2400 \mathrm{~cm}^{-1}$ indicated the presence of $\mathrm{C}-\mathrm{H}$ stretching. Fig. 4 shows the TEM spectra of MWCNT and ANMWC composite. As revealed antimony particles have been located well on the MWCNT surface.

\section{Contact time}

Contact time is one of the most important parameters in adsorption process. Considering that the adsorption process is one of equilibrium reactions, so the contact time plays an important role in reaction progress. As the adsorbates can easily access to absorption sites, the process requires less contact time to reach its maximum absorption ${ }^{18,19}$.
On the other hand, as the adsorbates cannot easily access to the adsorption sites, required contact time increased. Fig. 5 shows the effect of contact time on adsorption efficiency. Results revealed that the BPA removal efficiency by MWCNT increased from 51 to $87 \%$ with the increase of contact time 5 to $60 \mathrm{~min}$. In the mentioned range of contact time, the ANMWC composite efficiency in BPA removal increased from 80 to $93 \%$. As can be seen, the efficiency of ANMWC composite was better in BPA removal than that of MWCNT alone. This can be related to the influence of Antimony coated on the MWCNT surface. Dehghani et al. suggested that BPA removal increased with increasing contact time, which is in line with our result ${ }^{14}$. This result is also consistent with the finding of Samadi et $a^{R 0}$.

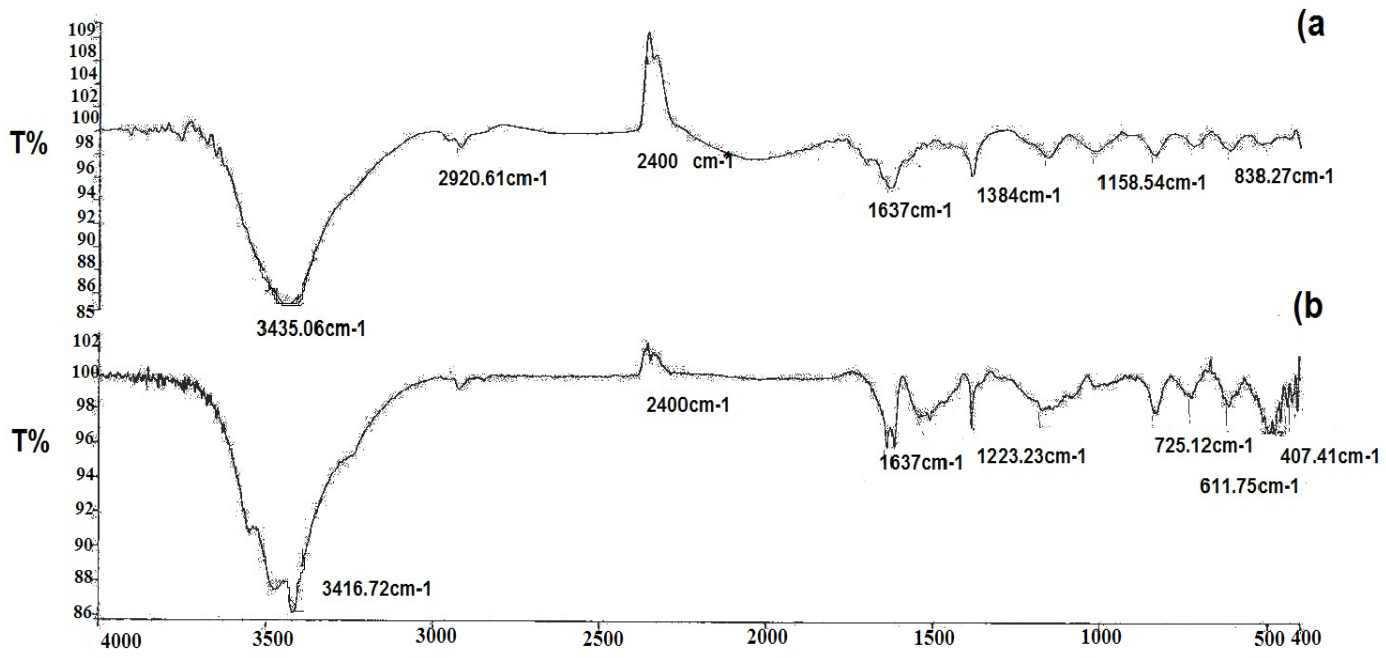

Fig. 3: FTIR spectra of ANMWC composite (a) before and (a) after adsorption process
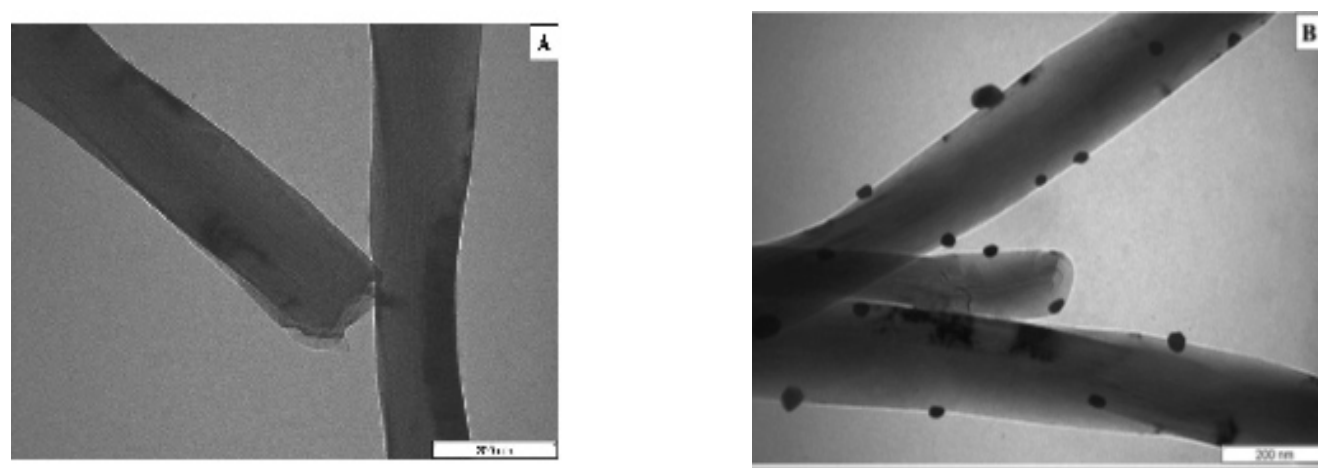

Fig. 4: TEM spectra of (a) MWCNT and (b) ANMWC composite 


\section{Effect of solution $\mathrm{pH}$}

Due to the direct effect of solution $\mathrm{pH}$ on the adsorbent surfaces and the degree of ionization of pollutants, it considered as the most important parameter in adsorption process ${ }^{21}$. Theoretically, $\mathrm{pH}$ can be affected on BPA absorption. As shown in fig.5, at acidic conditions, the removal efficiency of BPA increased gradually with increasing $\mathrm{pH}$. The maximum removal efficiency was seen at $\mathrm{pH} 7$, which was $85 \%$ for MWCNT and $95 \%$ for ANMWC composite. By contrast, with increasing $\mathrm{pH}$ values from 7 to 10 , the removal efficiency for both adsorbents decreased obviously. This can be attributed to the structure and $\mathrm{pH}_{\mathrm{zpc}}$ of adsorbent. According to the results obtained, $\mathrm{pH}_{\mathrm{zpc}}$ for both adsorbents was 7. When the $\mathrm{pH}$ of the solution is higher than the $\mathrm{pH}_{\mathrm{zpc}}$, absorbent surface becomes negatively charged and can adsorb well cations by the electrostatic reactions. On the other hand, at $\mathrm{pH}$ values higher than the $\mathrm{pH}_{\mathrm{zpc}}$, absorbent surface becomes positively charged and absorbs well anions. Considering the negative charge of BPA surface at alkaline conditions, the adsorption rate of BPA decreased. In contrast, because of positive charge of BPA at acidic conditions, the adsorption rate of BPA increased. In addition, at alkaline $\mathrm{pH}$, the degradation of $\mathrm{OH}^{-}$groups of phenolic compounds such as BPA, prevents the formation of hydrogen bonds between adsorbed BPA molecules on the surface of the nanotubes and molecules dissolved in solution and as a result, adsorption efficiency decreased ${ }^{22}$.

\section{Adsorption Isotherms and Kinetics Models}

According to the results, the correlation coefficient $\left(R^{2}\right)$ for both the absorbents in pseudo-first order model was relatively low. So, the pseudo-first order model did not fit with the experimental data well. Results showed that the adsorption process followed the pseudo-first order model with a high correlation value. Pseudo-first order model is in accordance to the adsorption capacity and it is used when the adsorption occurs using diffusion mechanism through a boundary layer. The pseudo-second order model showed that the chemical adsorption mechanism is dominant and controller and acts as a moderator in the adsorption process ${ }^{19}$.

In the present study, Langmuir and Freundlich isotherm models were investigated and the results of this stage are shown in Table 4. As can be seen here, in BPA adsorption on MWCNT, the correlation coefficient of Langmuir isotherm model (0.96) was higher than Freundlich isotherm model (0.82). Therefore, BPA adsorption on MWCNT followed the Langmuir isotherm model. Langmuir isotherm is the most common used isotherm to investigate the adsorption processes. This isotherm is based on the single-layer adsorption ${ }^{23}$. This isotherm indicated that adsorbate molecules were adsorbed on the specific points of adsorbent surface, which are called absorption sites.

The energy of adsorbates in each of adsorption sites is same and this not attributed to the presence or absence of adjacent adsorbed molecules. This assumption suggested that the energy levels are quite the same. Adsorption process is topically and occurred by colliding the adsorbates with empty sites. Finally, desorption rate depends only on the amount of material adsorbed

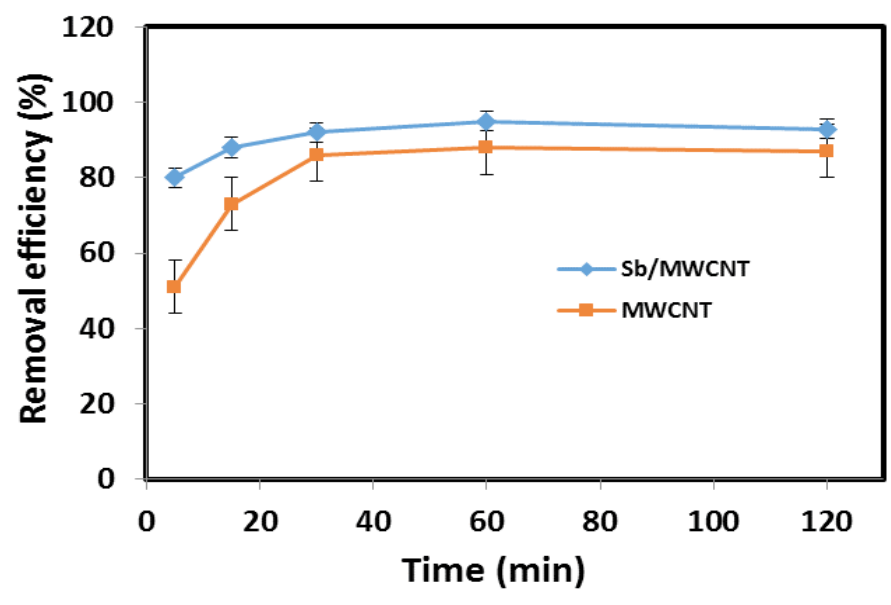

Fig. 5: 
on the surface ${ }^{19}$. a and $\mathrm{b}$ are Langmuir parameters, which indicated the maximum absorption capacity and correlation energy. While, the main feature of Langmuir isotherm is a dimensionless parameter called equilibrium $\left(R_{L}\right)$. The effectiveness of adsorption process in Langmuir model is determined by these parameters. $0<R_{L}<1$ indicate the suitable absorption, $1<R_{L}$ indicate unsuitable adsorption, and $R_{L}=0$ indicate irreversible absorption ${ }^{24}$. According to the $R_{L}$ value (0.046), which was obtained from the calculations (Table 4), the absorption process of BPA on MWCNT was a suitable process.

According to the results, the correlation coefficient of Freundlich isotherm model $(n=0.93)$ for the BPA absorption on ANMWC composite was higher than correlation coefficient of Langmuir isotherm model (0.81). As a result, the adsorption process followed the Freundlich isotherm model. Freundlich model defines the adsorption of adsorbates on heterogeneous surfaces and states that the adsorbates are adsorbed on the adsorbent as multilayer. $\mathrm{K}_{\mathrm{f}}$ and $\mathrm{n}$ are the constants, which are related to the adsorption capacity and absorption rate. The values of $\mathrm{n}<1$ indicate unsuitable adsorption, $1<\mathrm{n}<10$ indicate a suitable adsorption, $\mathrm{n}>1$ indicate stronger interactions between the absorbent and adsorbate, and $n=1$ indicates that the adsorption energy is the same for all sites (25). According to the $n$ value $(n=1.36)$, BPA absorption on ANMWC was suitable and there was a moderately strong interaction between adsorbate and adsorbent.
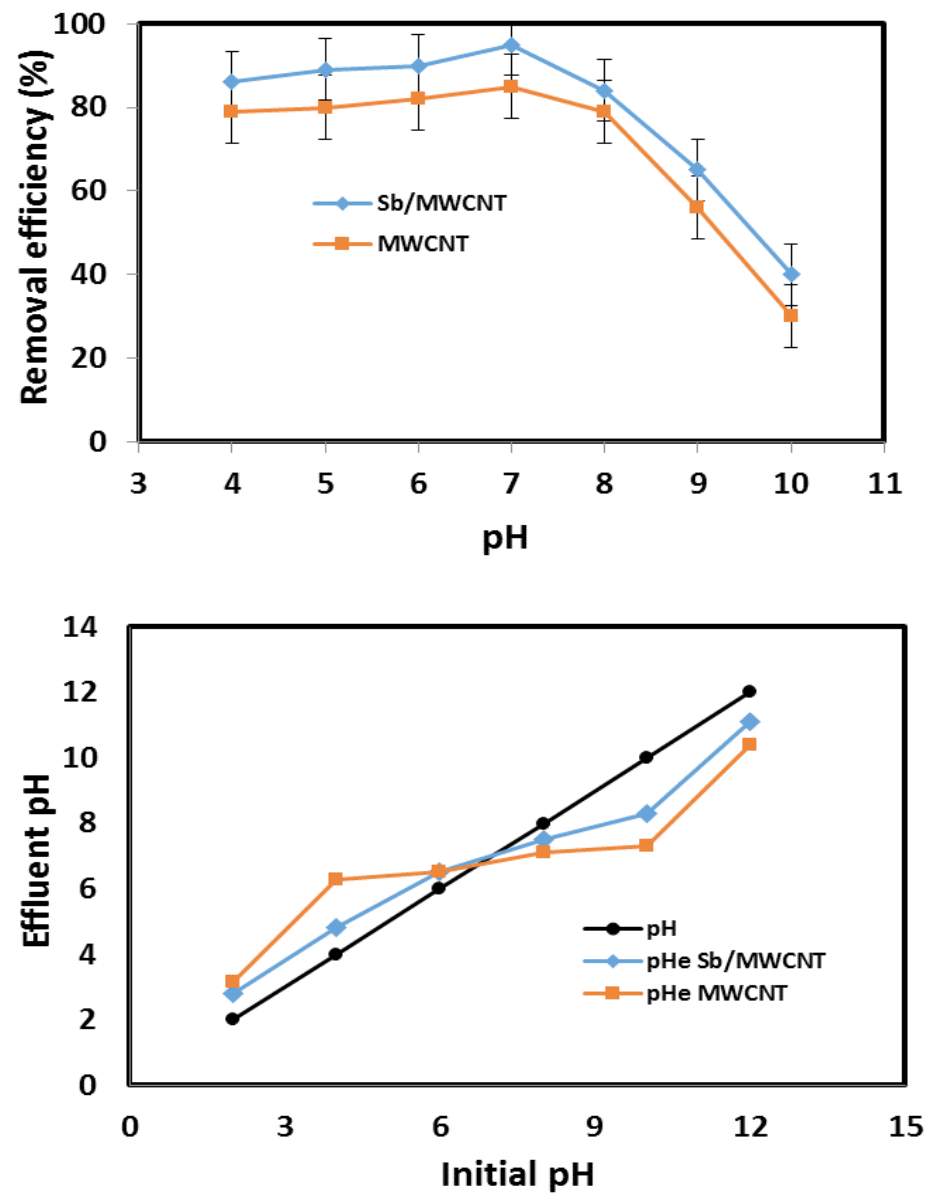

Fig. 6 

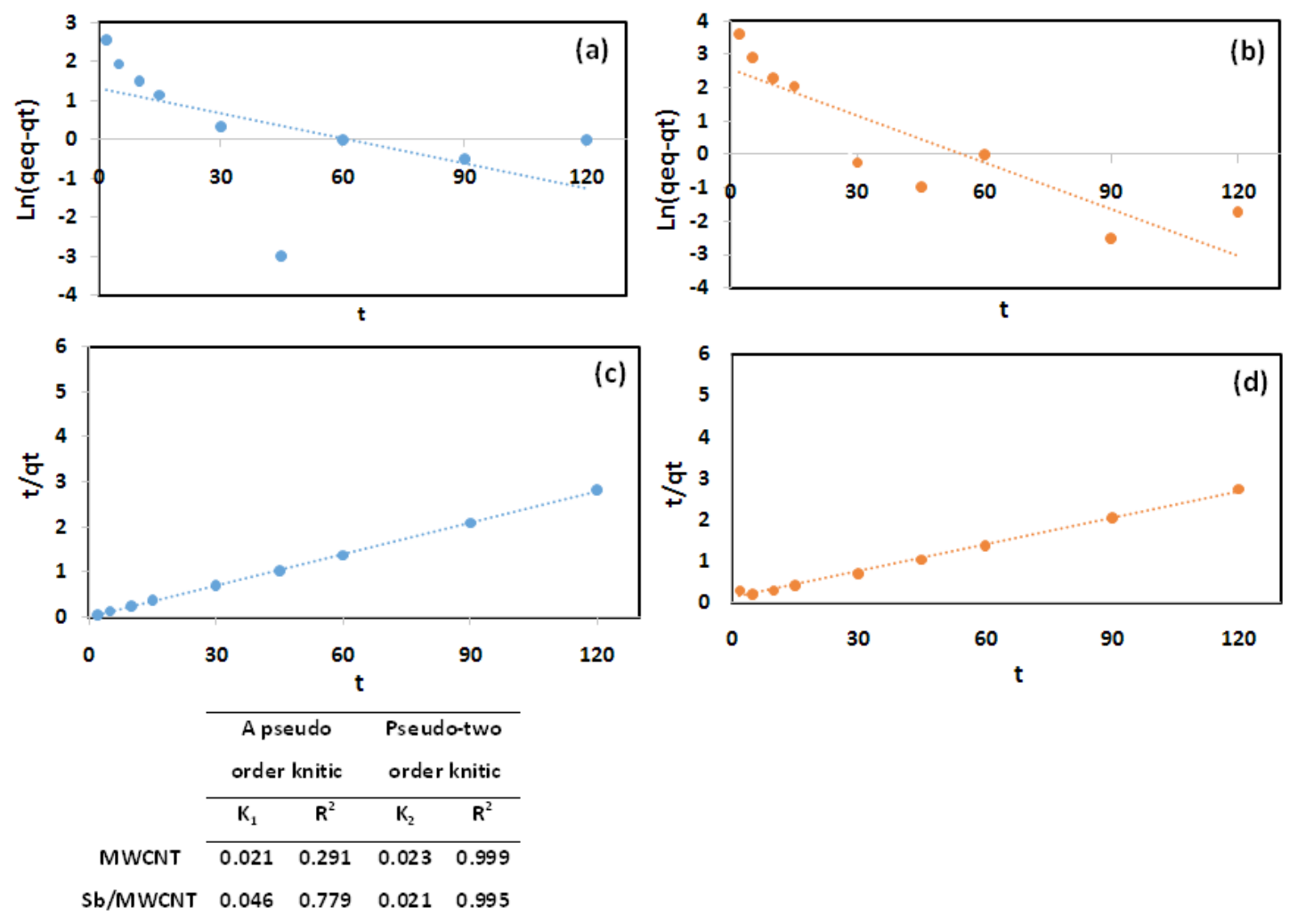

Fig. 7

\section{CONCLUSION}

The present focuses on preparing ANMWC composite as an adsorbent and then the effect of produced composite and MWCNT in BPA removal from aqueous solutions was studied. ANMWC were prepared using chemical method and characterized with X-ray diffraction (XRD), Fourier-transform infrared spectroscopy (FTIR) and Transmission Electron Microscope (TEM). Results revealed that the BPA removal efficiency by ANMWC increased from 80 to $93 \%$ with the increase of contact time 5 to $60 \mathrm{~min}$. The maximum removal efficiency was seen at $\mathrm{pH} 7$, which was $85 \%$ for MWCNT and $95 \%$ for ANMWC composite. According to the results obtained, $\mathrm{pH}_{\mathrm{zpc}}$ for both adsorbents was 7. Results showed that the adsorption process followed the pseudo-first order model with a high correlation value and BPA adsorption on MWCNT followed the Langmuir isotherm model. According to the results, the both MWCNT and ANMWC composite are effective for removing pollutants from aqueous solutions. Moreover, the ANMWC composite can be used as a suitable and new adsorbent for removing organic pollutants from water environments.

\section{ACKNOWLEDGMENT}

Authors would like to thank the Hamadan Laboratory, Graduate School of Medical Sciences for financial support of this research. This article is extracted from the Master's thesis (No, 9303131419). 


\section{REFERENCES}

1. Kalmykova, Y.; Moona, N.; Strömvall, A.M.; Björklund K. Sorption and degradation of petroleum hydrocarbons, polycyclic aromatic hydrocarbons, alkylphenols, bisphenol A and phthalates in landfill leachate using sand, activated carbon and peat filters. J Water Res. 2014, 51, 246-257

2. Huang, Y.Q.; Wong, C.K.C.; Zheng, J.S.; Bouwman, H.; Barra, R.; Wahlström, B., et al. Bisphenol A (BPA) in China: a review of sources, environmental levels, and potential human health impacts. J Environ Intern, 2012, 42, 91-99

3. Wang, J.; Schnute, W.C. Direct analysis of trace level bisphenol A, octylphenols and nonylphenol in bottled water and leached from bottles by ultrahighperformance liquid chromatography/tandem mass spectrometry. Rapid Commun Mass Spectrom.2010, 24, 2605-10

4. Sui, Q.; Huang, J.; Liu, Y.; Chang, X.; Ji, G.; Deng, S. Rapid removal of bisphenol a on highly ordered mesoporous carbon. Environ Sci. 2011, 23, 177-82

5. Samadi, M. T.; Zolghadrnasab, H.; Godini, K.; Poormohammadi, A.; Ahmadian, M.; Shanesaz S. Kinetic and adsorption studies of reactive black 5 removal using multi -walled carbon nanotubes from aqueous solution. Der Pharma Chemica. 2015, 7, 267-274

6. Heidari, Z.; Masrournia, M.; Sannavii Khoshnood, R. Fabrication a composite electrode based on MWCNT/Zeolite for potentiometric determination of $\mathrm{Cr}^{+}$. Orient J Chem. 2016, 32, 627-635

7. Zhang, Y. J.; Yang, J.; Liu, B. L.; X. u, Y. D. Removal of Copper lons from Water Using Chemical Modified Multi-walled Carbon Nanotubes. J Chem Soc Pakistan. 2014, 36, 841-847

8. Mohammadkhani, Sh.; Gholami M. R.; Aghaie, M. Thermodynamic study of $\mathrm{Cr}+3$ ions removal by "MnO2/MWCNT" nanocomposite. Orient J Chem.2016, 32, 592-599

9. Fernando, C.; Cesarinoa, I.; Cesarinoa, V.; Mascarob L, H.; Machadoa S, A. Carbon nanotubes modified with antimony nanoparticles: A novel material for electrochemical sensing. J Electrochim Acta i 2012, 85, 560-565

10. Putra E, K.; Pranowo R.; Sunarso J.; Indraswati N.; Ismadji S. Performance of activated carbon and bentonite for adsorption of amoxicillin from wastewater: mechanisms, isotherms kinetics. J Water Rese. 2009, 43, 2419-30

11. Saeedi, R.; Naddafi, K.; Nabizadeh, R. Lead (II) and cadmium (II) biosorption from aqueous by the Sargassum sp. biomass. $J$ Sch Public Health Inst Public Health Res. 2007, 5, 13-24

12. Kashitarash Isfahani, Z.; Samadi, M. T, Alavi, M.; Manuchehrpoor, N.; Bakhani, M. Efficiency of Carbon Nanotubes in Municipal Solid Waste Landfill Leachate (Case Study: Treatment of Hamadan Landfill Leachate). J .Water .Waste. 2011, 23, 67-72

13. Samadi, M. T.; Kashitarash Esfahani, Z.; Ahangari, F.; Ahmadi, S. H.; Jafari, S. J. Nickel Removal from Aqueous Environments Using Carbon Nanotubes. J .Water .Waste. 2012, 24, 38-44

14. Zazouli, M. A.; Balarak, D.; Mahdavi, Y.; Barafrashtehpour, M.; Ebrahimi, M. Adsorption of Bisphenol from Industrial Wastewater by Modified Red Mud. J health dev. 2013, 2, 1-11

15. Zhijian, L. i.; Gondal, M. A.; Yamani, Z. H. Preparation of magnetic separable CoFe2O4/ PAC composite and the adsorption of bisphenol A from aqueous solution. J. Saudi Chem. Soc. 2014, 18, 208-213

16. Dong, Y. I.; Deyi, W. U.; Chen, X.; Lin, Y. Adsorption of bisphenol A from water by surfactant-modified zeolite. J. Colloid Interface Sci. 2010, 348, 585-590

17. Zazouli, M. A.; Yousefi, Z.; Yazdani, J.; Tabarinia, H.; Tabarinia, F.; Akbari Adergani, B. Evaluation of L-Cysteine Functionalized Single-Walled Carbon Nanotubes On Mercury Removal from Aqueous Solutions. J Mazand Univ Med Sci. 2014, 24, 10-21

18. Uddin, M.T.; Islam, M.S.; Abedin, M.Z. Adsorption of phenol from aqueous solution by water hyacinth ash. ARPN J. Eng. Appl. Sci. 2007, 2, 11-17

19. Aksu, Z.; Yener, J. A comparative adsorption/ 
biosorption study of monochlorinated phenols onto various sorbents. J Waste Manage. 2001, 21, 695-702

20. Asgari, G.; Seid Mohammadi, A. M.; Poormohammadi, Ahmadian, M. Removal of Cyanide from Aqueous Solution by Adsorption onto Bone Charcoal. Fresen Environ Bull. 2014, 23, 720-727

21. Kakavandi, B.; Rezaei Kalantary, R.; Jonidi Jafari, A.; Esrafily, A.; Gholizadeh, A.; Azari, A. Efficiency of powder activated carbon magnetized by $\mathrm{Fe}_{3} \mathrm{O}_{4}$ nanoparticles for amoxicillin removal from aqueous solutions: Equilibrium and kinetic studies of adsorption process. Iran. J. Health \& Environ. 2014, 7, 34-21

22. Lin, D.; Xing, B. Adsorption of phenolic compounds by carbon nanotubes: role of aromaticity and substitution of hydroxyl groups. J. Environ. Sci. Technol. 2008, 42, 7254-59

23. $\mathrm{Wu}, \mathrm{J} . \mathrm{H}$.; Yu, Q. Biosorption of 2 , 4-dichlorophenol by immobilized white-rot fungus Phanerochaete chrysosporium from aqueous solutions. J Bioresour technol. 2007, 98, 253-259

24. Zheng, H.; Wang, Y.; Zheng, Y.; Zhang, H.; Liang, S.; Long, M. Equilibrium, kinetic and thermodynamic studies on the sorption of 4-hydroxyphenol on Cr-bentonite. J. Chem. Eng. 2008, 143, 117-23

25. Hameed, B.; Mahmoud, D.; Ahmad, A. Equilibrium modeling and kinetic studies on the adsorption of basic dye by a low-cost adsorbent: Coconut (Cocos nucifera) bunch waste. J Hazard Mater. 2008, 